\title{
Syme's Amputation: Do We Need It in 2020?
}

\author{
Uttam C Saini ${ }^{1}$, Sanjay S Rawat ${ }^{2}$, Mandeep S Dhillon ${ }^{3}$
}

\begin{abstract}
Syme's amputation was initially described during the pre-antisepsis and pre-antibiotic era and was found useful in many situations. Over time, this amputation technique lost favor due to associated complications and a cosmetically unacceptable prosthesis. The original technique was modified over the years, with reduced complications and improved outcomes and gait. We discuss here the evolution of Syme's amputation, its modifications, the importance of preoperative evaluation, and critical intraoperative steps for the success of the procedure.
\end{abstract}

Keywords: Ankle disarticulation, Boyd amputation, Heel pad, Modified pirogoff amputation, Syme's amputation.

Journal of Foot and Ankle Surgery (Asia Pacific) (2021): 10.5005/jp-journals-10040-1156

\section{BACKGROUND}

Syme's amputation/disarticulation is a procedure in which part of the lower limb distal to the ankle joint is removed with both malleoli. In this procedure, the surgeon preserves the heel pad after mobilizing it from the calcaneus to cover the distal stump for weight-bearing. Scottish surgeon James Syme first described this procedure in $1843^{1}$ (Fig. 1). It was first performed in a 16-year-old boy who was suffering from "caries of tarsus" (talus and calcaneum) with multiple discharging sinuses (probably tuberculosis), resulting in disease extending proximal to the limit of Chopart's amputation. The surgery was successful even in the pre-antisepsis and preantibiotic era and ended with a satisfied patient. The success of his first case at this level in the ankle led Syme to the conclusion that risk to life could be minimized with amputation at this level and providing a "seemlier limb" with a comfortable stump for progressive motion even without an orthosis. ${ }^{1-3}$

Around the same time, similar amputations were also described, namely Bauden's tibiotarsal amputation (1842), Roux's amputation (1845), Pirogoff's amputation (1854), and Guyon's amputation (1868). ${ }^{3}$ Nevertheless, Syme's amputation was proven to be superior to these, with better-documented outcomes over time. An ankle level amputation allows us to preserve more limb length, with the heel pad at the end of the residual limb, resulting in an end-bearing

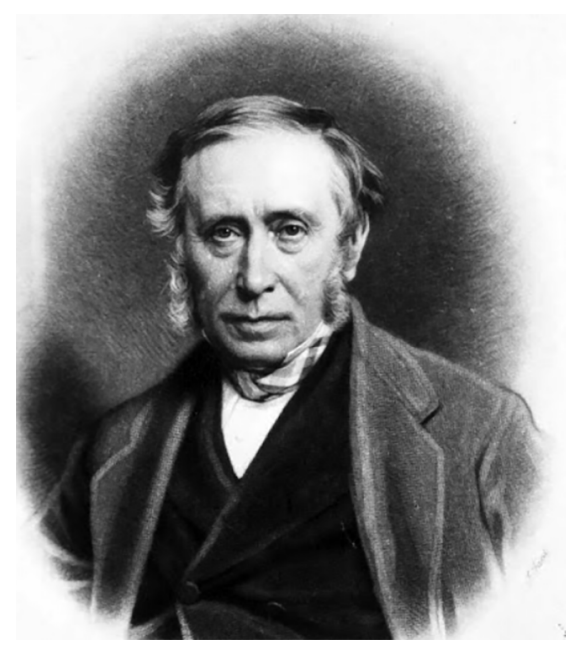

Fig. 1: Dr James Syme-Professor of surgery at Edinburgh University
${ }^{1-3}$ Department of Orthopaedics, Postgraduate Institute of Medical Education and Research, Chandigarh, India

Corresponding Author: Uttam C Saini, Department of Orthopaedics, Postgraduate Institute of Medical Education and Research, Chandigarh, India, Phone: +91 172-2756740, e-mail: doc.uttamsaini@gmail.com

How to cite this article: Saini UC, Rawat SS, Dhillon MS. Syme's Amputation: Do We Need It in 2020? J Foot Ankle Surg (Asia Pacific) 2021;8(2):86-90.

Source of support: Nil

Conflict of interest: None

stump. This combination enables short distance mobilization even without a prosthesis, which is not possible in higher-level amputations. $^{2}$ The heel pad is used for weight-bearing and has the advantage of intact proprioception in addition to it acting as a cushion.

Even today, indications for this amputation are, ranging from congenital deformities, traumatic or crush injuries (nonreconstructible forefoot and midfoot after complex trauma), tumors, osteomyelitis, frostbite, and peripheral vascular conditions (Fig. 2). In children, Syme's amputation had better results in terms

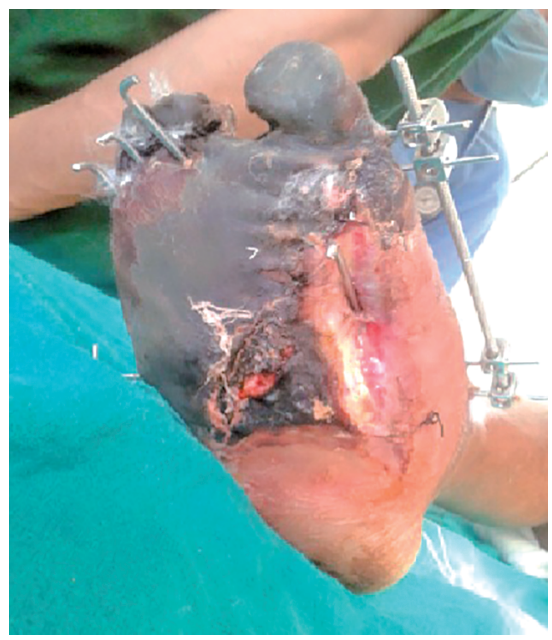

Fig. 2: Post-traumatic necrosis of foot extending beyond limit of Chopart's amputation: Indication for Syme's amputation

\footnotetext{
(c) The Author(s). 2021 Open Access This article is distributed under the terms of the Creative Commons Attribution 4.0 International License (https:// creativecommons.org/licenses/by-nc/4.0/), which permits unrestricted use, distribution, and non-commercial reproduction in any medium, provided you give appropriate credit to the original author(s) and the source, provide a link to the Creative Commons license, and indicate if changes were made. The Creative Commons Public Domain Dedication waiver (http://creativecommons.org/publicdomain/zero/1.0/) applies to the data made available in this article, unless otherwise stated.
} 
of the need for re-amputation, and there are added advantages. ${ }^{4}$ As compared to transtibial amputation, it preserves the growth plate of the distal tibia for future growth. Some complications associated with Syme's amputation, like infections, ulcerations, heel pad migration, flap necrosis, wound dehiscence, residual limb pain, and need for re-amputation at a higher level, are also seen with other amputations. ${ }^{2-8}$ Syme's amputation was seen as a promising alternative to below-knee amputation; however, it has lost its popularity over time and is underused by surgeons in modern orthopedics. ${ }^{5}$ Nevertheless, this is a valuable tool in the armamentarium of surgeons working in underdeveloped countries, and with this article, we hope to revitalize the interest in this amputation.

\section{Evolution of Syme's Amputation}

Syme's amputation was described as a single-stage procedure originally, but nowadays it may be done as a single-stage or twostage procedure. ${ }^{9-11}$ The aim behind the two-stage concept was to bring down the failure rate due to postoperative infection. Two-stage procedures are especially done in infected wounds that have higher chances of infection. Spittler et al. ${ }^{10}$ described and performed the two-stage procedure in a group of infected wounds. Ankle disarticulation is done in the first sitting with a "tension-free closure". The second procedure to remove lateral and medial malleoli is usually done after $6-8$ weeks. Wagner ${ }^{9}$ and Pinzur et al. ${ }^{11}$ propagated this procedure for diabetic foot and peripheral vascular diseases, respectively. This "staging procedure" has allowed the use of this surgery in the above groups of patients that were previously excluded.

Nevertheless, there are a few conditions when this procedure should be avoided, like low blood flow to the foot and ankle, severe immunocompromised or malnourished patients, cellulitis, and infection in the region. Wagner ${ }^{9}$ and Wagner ${ }^{12}$ have suggested that
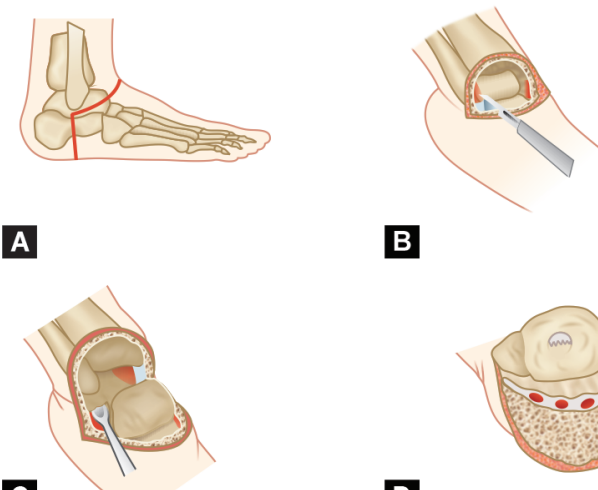

c

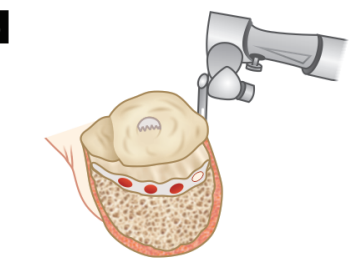

D
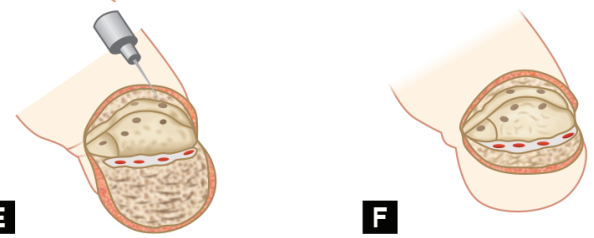

Figs 3 A to F: Diagram showing steps of Syme's amputation: (A) Incision marking; (B) Soft tissue dissection to the bone with incision of the anterior capsule of the ankle joint; (C) Subperiosteal dissection of the calcaneum. (D) Osteotomy of tibia and fibula parallel to the ground; (E) Drilling holes to anchor heel pad; (F) Closure with suturing of the heelpad to drilled holes over a drain after deflating the tourniquet if most distal skin of the amputation stump has not bled within 3 minutes, "serious thought should be given for amputation at a higher level". The procedure should be forsaken if bleeding is not seen even after 5 minutes and amputation needs to be done at a higher level.

\section{Surgical Technique ${ }^{1-3,13,14}$}

This procedure is usually performed in a supine-position under a tourniquet. Bony landmarks are marked, and fish mouth incision is given from lateral malleolus to $1.5 \mathrm{~cm}$ distal to medial malleolus (Fig. 3). From here cut is taken plantar-wards directly across the sole to meet at the lateral malleolus (crossing around calcaneocuboid joint or $6-7 \mathrm{~cm}$ from the heel). The aim is to create a posterior heel flap without damaging the fat pads. Dissection is done directly to the bone. The extensor tendons are stretched, transected, and allowed to retract proximally, and the foot is moved into the equinus to incise the anterior capsule. The talar neck is reached after cutting ligaments from both sides of the talus, freeing it so it can be dislocated to visualize and divide the posterior joint capsule. Take care not to injure the posterior tibial artery around the medial malleolus. The Achilles tendon is now exposed and separated from the calcaneus, avoiding injury to overlying skin. The dissection is now carried on in the subperiosteal plane around the calcaneum, starting from the superolateral surface of the calcaneum. The distal foot is now removed, leaving the heel flap. Devitalized tissues and hidden pockets of infection are to be identified at this stage, thoroughly debrided, and irrigated. With careful flap protection, an incision is given over the periosteum $0.6-1.5 \mathrm{~cm}$ proximal to the joint line circumferentially, to achieve a broad base for better weight transmission after the amputation. Posterior tibial vessels are now isolated and ligated. The subcutaneous fat and septa of the heel flap are carefully preserved, as these are one of the critical components of postoperative weight-bearing. The position of this heel flap is also crucial, and various techniques have been advised and adopted to prevent heel pad migration, $3,6-8,15,16$ these include adhesive taping, fixing with k-wire or Steinman pins (Fig. 4), or leaving behind a flake of calcaneum fixed to the heel flap, which fuses to the distal tibia. The closure is done by approximating the anterior and posterior flaps (Fig. 5). No effort should be applied to remove the dog ears as it hampers the blood flow in the heel-pad and usually disappears over time. The closure is done over the drain (Fig. 6), and particular emphasis is given during surgery to avoid damaging the posterior tibial neurovascular bundle, subperiosteal heel flap dissection from the calcaneus, and proper drainage of any dead space.

Postoperatively, a well-padded plaster cast is applied to prevent heel pad shifting during the first $4-6$ weeks. Pain medications and antibiotics are given to the patient as required. The plaster cast is changed every 2 weeks till the shrinkage has slowed and edema is

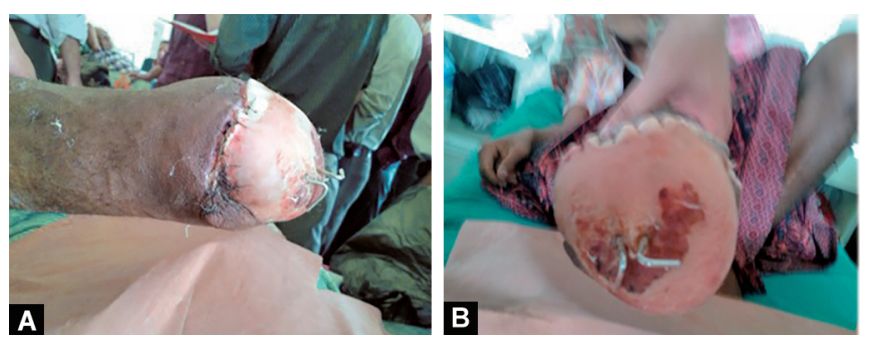

Figs 4A and B: In situ K-wires to hold heel pad in position and prevent flap migration 

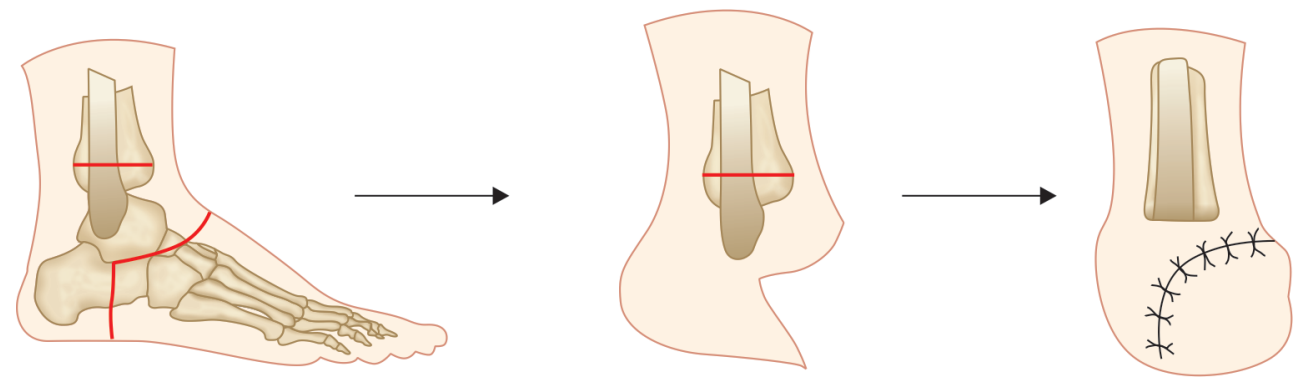

Fig. 5: Technique of Syme's amputation showing incision, removal of the hindfoot, and closure of stump
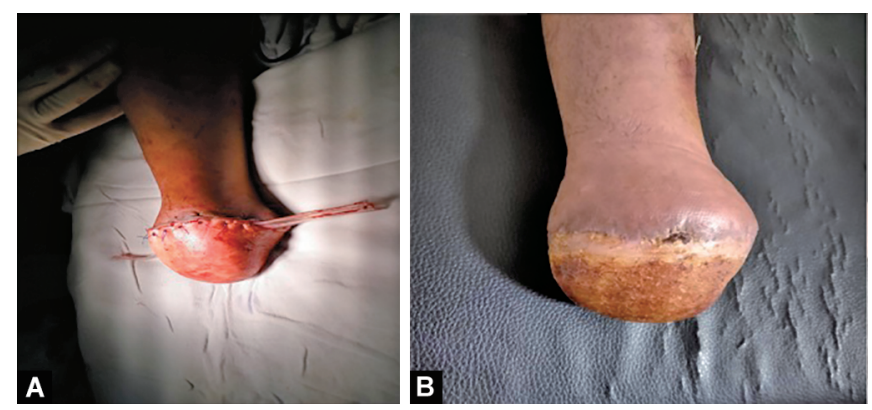

Figs $6 \mathrm{~A}$ and B: Condition of the stump: (A) Immediate postoperative stump with drain in situ; (B) Healed stump

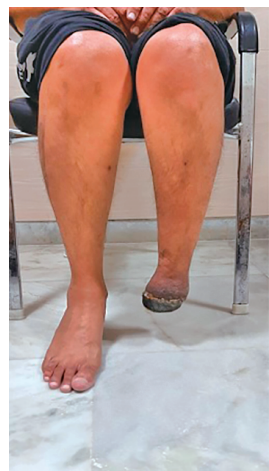

A

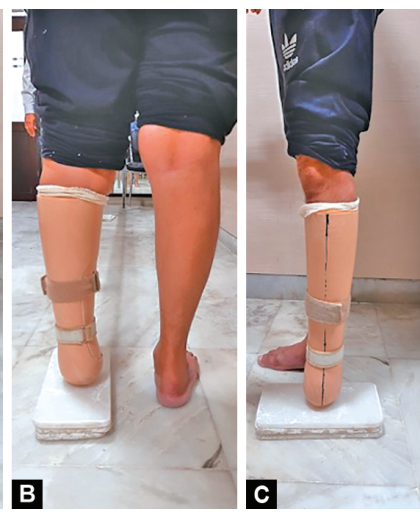

c

Figs 7A to C: Pictures of a patient at prosthesis fitting $(A)$ with measurements being taken for a prosthesis (B and $C$ )
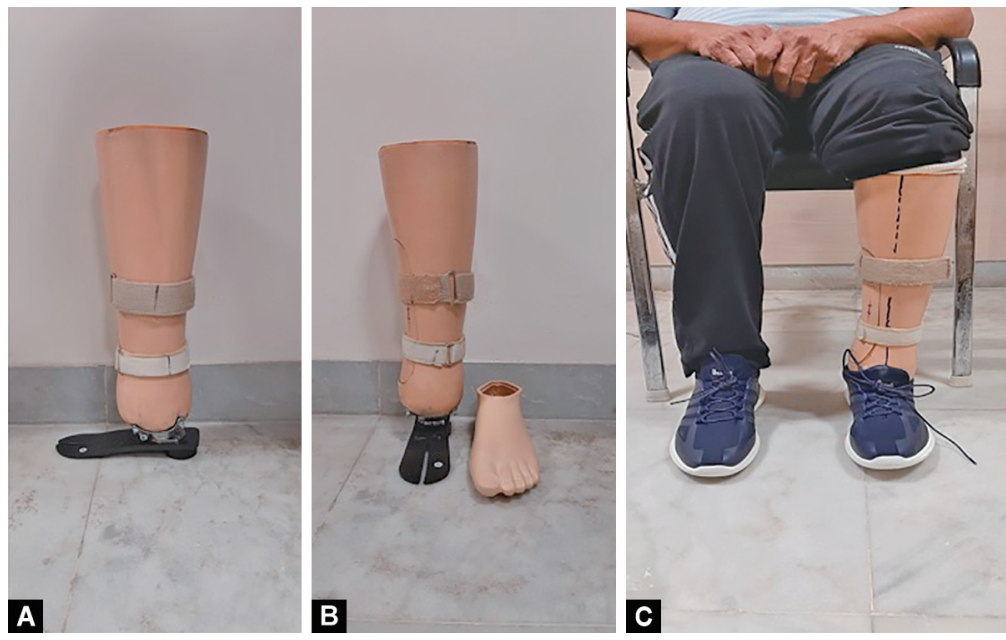

Figs 8A to C: Prosthesis for Syme's. (A) Syme's prosthesis; (B) Prosthesis with foot; (C) Patient with prosthesis and shoe wear

resolved. Do not allow the patient to bear weight for 6 weeks after that patient may be allowed to take the weight with a snuggly fitting cast. The final prosthesis can be fitted once the stump is healed and become stable (Figs 7 and 8). Patients need extensive rehabilitation and modification in their activities to regain full function after amputation surgery.

\section{Modifications to the Original Technique Over Time}

Many authors have advised modification over time, mainly to prevent heel pad migration, as it could occur in $7.5-45 \%$ of patients. ${ }^{8}$ Bibbo ${ }^{6}$ suggested fixing the anterior edge of the plantar flap to distal tibia and peroneal tendons to be fixed to the lateral border of the heel-pad to stabilize it. Tendo-Achilles tenodesis to the tibia was suggested by Smith et al. ${ }^{7}$ to help in neutralizing the deforming force of this tendon and may help in healing by taking off tension from the incision site. Smith et al. ${ }^{8}$ suggested fixing the plantar fascia to the lateral surface of the tibia, to prevent varus migration of the heel pad. Wagner ${ }^{9}$ advised suturing of heel flap to the tibia and fibula through multiple drilled holes. Sarmiento ${ }^{16}$ advised resection of the distal tibia and fibula 1 to $1.5 \mathrm{~cm}$ above the ankle joint to form a more cosmetic and less bulbous stump. Mathur et al. ${ }^{15}$ suggested modifications in Syme's amputation such as a smaller heel flap, the tibia, and fibula to be cut around $1.2 \mathrm{~cm}$ above the articular surface, and the heel pad firmly fixed to the cut end of the bone by suturing it to the flap of the tibial periosteum. These changes give a less bulbous distal end, which allows the fabrication and fitting of a cosmetically acceptable prosthesis. The authors realized that they were reducing the weight-bearing area of 
the stump, which was compensated with partial end bearing and partial proximal tibia weight-bearing prosthesis.

Pirogoff's amputation, described in 1854, saved a piece of calcaneum in the posterior flap, which is dissected out in Syme's amputation. It was developed to minimize the devascularization of flap and limb length discrepancy. ${ }^{14,17}$ In modified Pirogoff's amputation, initial steps are similar to Syme's description, after which the forefoot is then excised at the calcaneocuboid joint, preserving the calcaneum with the heel pad. A vertical calcaneal osteotomy is done perpendicular to the long axis of the calcaneum along with another osteotomy at the upper end is done which leaves a $60^{\circ}$ cut portion of the top of the calcaneum. The tibia plafond is cut along with medial and lateral malleolus, perpendicular to the long axis. Now the flap is turned forward to position the cut surface of calcaneum in apposition with the cut surface of the tibia and provisionally fixed and checked under C-arm and finally fixed with the screws.

The Boyd amputation ${ }^{14}$ is quite similar to Syme's amputation with few variations in its technique, as it preserves a part of calcaneum in addition to the intact heel pad. In comparison to Syme's amputation, a longer anterior and short posterior flap is used in Boyd amputation. Initial surgical steps are similar after which the anterior segment of the calcaneus is removed by horizontal osteotomy, distal to peroneal tubercle, and tibia and fibula are prepared after removal of cartilage for arthrodesis with calcaneus. Calcaneus is shifted forward into the mortise for arthrodesis with its under-surface being parallel to the ground. Fixation can be done as preferred by the surgeon with Steinman pin or screws, passing till tibia from calcaneum in the desired position. Kornah ${ }^{18}$ suggested that the problem of obtaining a sound calcaneotibial fusion could be solved by using the talus as a graft after preparing its surfaces and sandwiching it between tibia and calcaneum, along with tenotomy of the Achilles tendon.

\section{Do We Need the Syme's Amputation TODAY?}

Two big problems associated with Syme's amputation in the early part of the last century were a higher incidence of infection with wound healing complications and ill-fitting and unsightly prosthesis. But proper patient selection after preoperative evaluation (assessment of foot perfusion, heel pad status, immune and nutritional status) has resulted in increased success rates and decreased associated complications. ${ }^{19}$ Pinzur et al. ${ }^{20}$ observed that a success rate of around $88 \%$ could be achieved if all criteria for nutrition and vascular flow were fulfilled. Initially, diabetic patients were excluded, as the outcome was not favorable in these patients; with recent advances and the option of a two-staged procedure, amputation is possible even in this subgroup. Also, the emergence of revascularization of the limb in arteriosclerosis patients has allowed the option of Syme's in these patients, which otherwise would have landed with proximal level amputations. Newer advances in prosthetic designs have brought in cosmetically acceptable and lighter versions, leading to equal acceptability in both genders. With proper gait training, near-normal gait is achievable as the intact long lever arm of tibia and fibula along with heel pad proprioception is a big advantage. ${ }^{21}$

Pinzur et al. ${ }^{20}$ recorded that mortality in Syme's amputation was much lower compared to higher-level amputations, as increased cardiac stress with a more proximal amputation level was observed more frequently. It was also observed that there is a decrease in walking speed and cadence as the level of amputation shifts more proximal. ${ }^{20,22}$ The simplicity of rehabilitation is due to reduced energy demand from amputation at the ankle level, in contrast to the higher level of amputation, and the advantage of the decreased requirement of energy and metabolic expenditure

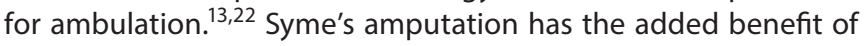
simple gait patterns, and reduced probability of soft tissue failure as compared to Lisfranc and Chopart amputations, ${ }^{23-25}$ and the stumps are more comfortable to fit with a modern prosthesis.

To conclude, Syme's amputation is a procedure with less mortality and morbidity. It also has decreased cardiac stress in contrast to a higher level of surgery. When the procedure is done in selected patients after a thorough preoperative evaluation and adhering to appropriate principles, complications are minimal, and outcomes are good. The necessary steps that increase the surgical success rates are preserving the blood supply of the heel flap, appropriate removal of the malleoli and cartilage to create broad distal support, and appropriately securing the heel flap to tibia and fibula. The patient should be counseled regarding the limitations of the procedure, rehabilitation protocols, and the expected outcomes.

\section{References}

1. Syme J. Amputation at the ankle joint. Lond and Edinburgh. J Med Sci 1843;3:93-96.

2. Harris RI. Syme's amputation; The technical details essential for success. J Bone Joint Surg Br 1956;38-B(3):614-632. DOI: 10.1302/0301620X.38B3.614.

3. Harris RI. The history and development of Syme's amputation. Artif Limbs 1961;6:4-43.

4. Braaksma R, Dijkstra PU, Geertzen JHB. Syme amputation: a systematic review. Foot Ankle Int 2018;39(3):284-291. DOI: 10.1177/1071100717745313.

5. Hudson JR, Yu GV, Marzano R, et al. Surgical technique, prosthetic considerations, and case reports. J Am Podiatr Med Assoc 2002;92:15.

6. Bibbo C. Modification of the syme amputation to prevent postoperative heel pad migration. J Foot Ankle Surg 2013;52(6):766-770. DOI: 10.1053/j.jfas.2013.07.006.

7. Smith DG, Sangeorzan BJ, Hansen ST, et al. Achilles tendon tenodesis to prevent heel pad migration in the syme's amputation. Foot Ankle Int 1994;15(1):14-17. DOI: 10.1177/107110079401500104.

8. Smith NC, Stuck R, Carlson RM, et al. Correction of varus heel pad in patients with Syme's amputations. J Foot Ankle Surg Off Publ Am Coll Foot Ankle Surg 2012;51(3):394-397. DOI: 10.1053/j.jfas.2012 .02 .001 .

9. Wagner FW,Jr. The syme amputation. In: Atlas of Limb Prosthetics Bowker J, Michael J, ed., St. Louis: C.V. Mosby, pp. 413-422. http:// www.oandplibrary.org/alp/chap17-01.asp (accessed 2 Oct2020).

10. Spittler AW, Brennan JJ, Payne JW. Syme amputation performed in two stages. J Bone Joint Surg Am 1954;36-A(1):37-42. DOI: 10.2106/00004623-195436010-00005passim.

11. Pinzur MS, Smith D, Osterman H. Syme ankle disarticulation in peripheral vascular disease and diabetic foot infection: the one-stage versus two-stage procedure. Foot Ankle Int 1995;16(3):124-127. DOI: $10.1177 / 107110079501600303$.

12. Wagner FW. Amputations of the foot and ankle. Current status. Clin Orthop 1977. 62-69.

13. Yu GV, Schinke TL, Meszaros A. Syme's amputation: a retrospective review of 10 cases. Clin Podiatr Med Surg 2005;22(3):395-427. DOI: 10.1016/j.cpm.2005.03.008. 
14. Richardson DR. Amputations of the foot. In: Canale ST, Beaty JH, ed. Campbell's Operative Orthopaedics. 12th ed., Elsevier; 2013.

15. Mathur BP, Piplani CL, Majid MA. A new approach to symes and its prosthesis. Orthot Prosthet 1985;39:47-52.

16. Sarmiento A. A modified surgical-prosthetic approach to the Syme's amputation. A follow-up report. Clin Orthop 1972;85:11-15. DOI: 10.1097/00003086-197206000-00004.

17. Nather A, Wong KL, Lim AS, et al. The modified Pirogoff's amputation in treating diabetic foot infections: Surgical technique and case series. Diabet Foot Ankle 2014;5(1):23354. DOI: 10.3402/dfa.v5.23354.

18. Kornah B. Modified boyd amputation. J Bone Joint Surg Br 1996;78B(1):149-150. DOI: 10.1302/0301-620X.78B1.0780149.

19. Finkler ES, Marchwiany DA, Schiff AP, et al. Long-term outcomes following syme's amputation. Foot Ankle Int 2017;38(7):732-735. DOI: 10.1177/1071100717702462.

20. Pinzur MS, Stuck RM, Sage R, et al. Syme ankle disarticulation in patients with diabetes. J Bone Jt Surg-Am 2003;85(9):1667-1672. DOI: 10.2106/00004623-200309000-00003.
21. Brand RA. An improved prosthesis for a syme amputation: Rex L. Diveley MD, Richard H. Kiene MD. Clin Orthop 2008;466(1):127-129. DOI: 10.1007/s11999-007-0027-0.

22. Waters RL, Perry J, Antonelli D, et al. Energy cost of walking of amputees: the influence of level of amputation. J Bone Joint Surg Am 1976;58(1):42-46. DOI: 10.2106/00004623-19765801000007.

23. Lindqvist C, Riska EB. Results after amputations of Chopart, Pirogoff and Syme. Acta Orthop Scand 1965;36:344-345.

24. Brosky TA, Hudson JR, Yu GV. Utilizing threaded steinmann pins to resect the talus and calcaneus for ankle joint disarticulation (Syme's procedure). J Foot Ankle Surg 2000;39(1):59-60. DOI: 10.1016/S10672516(00)80066-6.

25. Greene WB, Cary JM. Partial foot amputations in children. A comparison of the several types with the Syme amputation. J Bone Joint Surg Am 1982;64(3):438-443. DOI: 10.2106/00004623198264030-00015. 